\title{
Withholding and Withdrawal of Life Support in Mechanically Ventilated Stroke Patients
}

Etienne de Montmollin ( $\nabla$ etienne.demontmollin@aphp.fr )

Hopital Bichat - Claude-Bernard, APHP https://orcid.org/0000-0001-6379-1928

\section{Carole Schwebel}

Centre Hospitalier Universitaire Grenoble Alpes

\section{Claire Dupuis}

Centre Hospitalier Universitaire de Clermont-Ferrand

\section{Maité Garrouste-Orgeas}

Institut Hospitalier Franco-Britannique

\section{Daniel da Silva}

Centre Hospitalier de Saint Denis

Elie Azoulay

Hopital Saint Louis

\section{Virginie Laurent}

Centre Hospitalier de Versailles

\section{Guillaume Thiéry}

Centre Hospitalier Universitaire de Saint-Etienne

\section{Alexandra Grinea}

Hopital Bichat - Claude-Bernard

\section{Guillaume Marcotte}

Groupement Hospitalier Edouard Herriot

\section{Johanna Oziel}

Hopital Avicenne

\section{Marc Gainnier}

Hopital de la Timone

\section{Shidasp Siami}

Centre Hospitalier Sud-Essonne Site d'Etampes

\section{Jean Reignier}

Centre Hospitalier Universitaire de Nantes

\section{Benjamin Sztrymf}

Hopital Antoine-Beclere

\section{Christophe Adrie}

Hopital Cochin

\section{Stephane Ruckly}


Université de Paris

Romain Sonneville

Hopital Bichat - Claude-Bernard

Jean-François Timsit

Hopital Bichat - Claude-Bernard

Research

Keywords: Ischemic stroke, Intracerebral hemorrhage, Subarachnoid hemorrhage, end-of-life care, mechanical ventilation

Posted Date: August 25th, 2020

DOI: https://doi.org/10.21203/rs.3.rs-62282/v1

License: (c) (i) This work is licensed under a Creative Commons Attribution 4.0 International License. Read Full License 


\section{Abstract}

Background. The determinants of decisions to limit life support (withholding or withdrawal) in ventilated stroke patients have been poorly investigated.

Methods. In a prospective multicenter observational cohort (2005-2016), we evaluated limitation of life support in ventilated stroke patients compared to a non-brain-injured population and identified factors associated with such decisions in stroke patients using Fine and Gray competing risk models.

Results. We identified 373 stroke patients (ischemic, $n=167$ (45\%); hemorrhagic, $n=206$ (55\%)), and 5683 non-brain-injured patients. Decisions to limit life support were taken in $41 \%$ of ischemic stroke cases (vs. non-brain-injured patients, sHR 3.59 [95\% Cl 2.78-4.65]) and in 33\% of hemorrhagic stroke cases (vs. nonbrain-injured patients, sHR 3.9 [95\% Cl 2.97-5.11]). Time from ICU admission to the first limitation was longer in ischemic than in hemorrhagic stroke (5 [3 - 9] vs $2[1$ - 6] days, $p<0.01)$. Limitation of life support preceded ICU death in $70 \%$ of ischemic strokes and $45 \%$ of hemorrhagic strokes $(p<0.01)$. Life support limitation in ischemic stroke was associated with a vertebrobasilar location (vs. anterior circulation, sHR, 1.61 [95\% $\mathrm{Cl} 1.01-2.59])$ and in hemorrhagic stroke, it was associated with an age $>70$ years (2.29 [1.43 3.69]), a Glasgow score<8 (2.15 [1.08 - 4.3]) and a lower non-neurologic admission SOFA score (per point, $0.89[0.82-0.97])$.

Conclusions. In ventilated stroke patients, decisions to limit life support are more than 3 times more frequent than in non-brain injured patients, with different timing and associated risk factors between ischemic and hemorrhagic strokes.

\section{Background}

The prognosis of mechanically ventilated stroke patients is poor, with 1-year mortality rates ranging from $60-92 \%[1-5]$. In this subset of extremely severe cases with high fatality rates, a high incidence of limitation (withholding or withdrawal) of life support has been reported, ranging from 30 to $40 \%$ [6-8] compared to $9-14 \%$ in large multicenter observational studies in the general Intensive Care Unit (ICU) population [9-15]. Compared to non-brain-injured critically ill patients, the decision to limit life support in brain-injured patients may have more serious consequences, as the continuation of organ support could result in months or years of life in a state of disability that may be against the patient's wishes [16]. Assessing long-term vital and functional outcomes in these patients is difficult, and current prognostic models do not include treatment restrictions that can affect the outcomes of the populations in which the models were developed [17].

The high incidence of life support limitation in mechanically ventilated stroke patients and the potential confounding impact on prognostication models suggests that determinants of limitation of life support should be thoroughly investigated. In this observational multicenter study, we sought to describe the incidence, timing, and factors associated with life-support limitation in critically ill patients, with either ischemic or hemorrhagic stroke, requiring invasive mechanical ventilation (IMV). 


\section{Methods}

\section{Patient data source}

This observational cohort study was conducted using data from the French prospective multicenter $(\mathrm{n}=$ 28 ICUs) OUTCOMEREA database. Patients admitted between 2005 and 2016 were considered for this study. We chose 2005 as the beginning of the study period as important end-of-life legislation was acted in France that year. The OUTCOMEREA database, described in previous publications [18], has been approved by the French Advisory Committee for Data Processing in Health Research and the French Informatics and Liberty Commission (CNIL, registration no. 8999262). The database protocol was submitted to the Institutional Review Board of the Clermont-Ferrand University Hospital (ClermontFerrand, France), who waived the need for informed consent (IRB no. 5891). The datasets used during the current study are available from the corresponding author on reasonable request.

\section{Study populations and definitions}

The stroke population included all adult patients with acute stroke and requiring IMV within $24 \mathrm{~h}$ of ICU admission. ICU stays were considered as related to acute stroke in cases of: 1) direct ICU admission following stroke onset, or 2) ICU admission during the initial acute care hospital stay following stroke onset. We excluded patients without hospitalization reports. From the same ICUs where the stroke population was selected, we defined a non-brain-injured population comprised of non-stroke adult patients requiring IMV within $24 \mathrm{~h}$ of ICU admission, and without admission diagnoses associated with brain injury: cardiac arrest, status epilepticus, meningitis/encephalitis, and traumatic brain injury.

Intracranial hemorrhages and subarachnoid hemorrhages were merged as "hemorrhagic strokes" [19]. Limitations of life support were categorized as either withholding or withdrawing. Withholding of life support was defined as a decision not to start or increase a life-sustaining intervention. Withdrawal of life support was defined as a decision to actively stop a life-sustaining intervention presently underway [20]. If more than one limitation decision occurred for a single patient, the most active limitation (withdrawing > withholding) defined the limitation category. End-of-life outcomes were categorized as follows: 1) death without limitation if death occurred in absence of any decision to limit life support, 2) death following limitation if death occurred after any limitation of life support, and 3) brain death, in cases of documented cessation of cerebral function [20]. The severity of illness was graded at ICU admission with the use of the Simplified Acute Physiology Score (SAPS) II [21] and the sequential organ failure assessment (SOFA) score [22]. The non-neurologic SOFA was defined as the SOFA score without the neurologic component. Coma was defined as a Glasgow coma score $(G C S)<8$ [23]. We used the Charlson comorbidities index to assess the burden of comorbid conditions [24].

\section{Data collection}

Data were prospectively collected at admission and daily throughout the ICU stay, through an anonymized electronic case report form using Vigirea, Rhea, and e-Rhea software (OutcomeRea, Aulnaysous-Bois, France). Long term survival after hospital discharge was collected by each local investigator. 
We retrospectively collected the following data in medical charts: date of stroke, location and acute phase therapy (i.e. thrombolysis or endovascular thrombectomy for ischemic strokes and neurosurgery or embolization for hemorrhagic strokes).

\section{Statistical analysis}

Quantitative variables are presented as medians, 1 st and 3rd quartiles, and compared between groups with the Wilcoxon test. Qualitative variables are presented as frequencies and corresponding percentages and compared with the Chi-square test or Fisher exact test, as appropriate.

To compare the risk of life support limitation between stroke and non-brain-injured populations, we used an adjusted Fine and Gray sub-distribution competing risk model [25] to estimate the sub-distribution hazard of stroke as a class variable (ischemic stroke/hemorrhagic strokes/no stroke), and considering ICU death without limitation as the competing event. For each stroke subgroup, factors associated with the occurrence of a limitation of life support were evaluated using a Fine and Gray model [25], with the same competing event. All models were adjusted on non-collinear factors associated $(p<0.1)$ with the outcome of interest in univariate analysis using a backward selection procedure. The log-linearity of quantitative variables included in the models was tested. When this was not the case, variables were binarized using the median as the cutoff. To account for variability in practice of life support limitation across ICUs $[12,26]$, models were stratified on center (centers with less than $10 \%$ of the cohort were combined into one stratum). Two-by-two clinically relevant interactions were tested in each model. Missing data were all completely at random with less than $10 \%$ missing values per variable, and were handled by simple imputation with the median/most frequent method [27]. For each stroke subgroup, we conducted a sensitivity analysis by forcing in the models the period of study inclusion, arbitrarily divided into 4-year time intervals.

All statistical analyses were carried out with SAS 9.4 (SAS Institute Inc., Cary, NC, USA). A p-value of 0.05 and lower was considered statistically significant.

\section{Results}

Among 17520 ICU admissions over the study period, we identified 373 acute stroke patients from 14 ICUs where IMV was initiated within $24 \mathrm{~h}$ of admission. In the same 14 ICUs, we identified 5683 non-braininjured patients (Additional file 1). Stroke patients were predominantly male (59\%), aged 68.7 [58.2-76.5] years, with strokes classified as ischemic $(n=167,45 \%)$ and hemorrhagic $(n=206,55 \%)$. Patients' characteristics according to stroke type or absence of brain injury are presented in Table 1. Ischemic stroke patients were admitted to university hospitals in $92 / 167(55 \%)$ cases, hospitals with a stroke unit in 160/167 (96\%) cases, and with a neurosurgery unit and interventional radiology in 80/167 (48\%) cases. Hemorrhagic stroke patients were admitted to university hospitals in 131/206 (64\%) cases, hospitals with a stroke unit in 182/206 (88\%) cases, and with a neurosurgery unit and interventional radiology in $107 / 206(48 \%)$ cases. 
Table 1

Population characteristics according to stroke subtype or absence of brain injury

\begin{tabular}{|c|c|c|c|c|}
\hline $\begin{array}{l}\text { Variable } \\
\text { N (\%) or median [Q1 - Q3] }\end{array}$ & $\begin{array}{l}\text { Non-brain-injured } \\
\text { patients } \\
n=5683\end{array}$ & $\begin{array}{l}\text { Ischemic stroke } \\
\text { patients } \\
n=167\end{array}$ & $\begin{array}{l}\text { Hemorrhagic stroke } \\
\text { patients }^{a} \\
n=206\end{array}$ & $\mathrm{p}^{b}$ \\
\hline \multicolumn{5}{|l|}{ Demographics/history } \\
\hline Age, years & $62.4[49.4-74]$ & $\begin{array}{l}69.6[61.2- \\
77.2]\end{array}$ & $67[56.6-76.4]$ & 0.09 \\
\hline Male sex & $3506(61.7)$ & $112(67.1)$ & $109(52.9)$ & $<.01$ \\
\hline $\begin{array}{l}\text { Charlson comorbidity index } \\
\geq 1\end{array}$ & $3810(67)$ & $103(61.7)$ & $97(47.1)$ & $<.01$ \\
\hline \multicolumn{5}{|l|}{ ICU characteristics } \\
\hline University affiliated ICU & $3846(67.7)$ & $92(55.1)$ & $131(63.6)$ & 0.10 \\
\hline GCS at admission & $12[5-15]$ & $6[3-10]$ & $3[3-6]$ & $<.01$ \\
\hline SAPS II & 50 [37-64] & $56[45-67]$ & $61[52-77]$ & $<.01$ \\
\hline ICU length of stay, days & $6[3-13]$ & $7[4-13]$ & $3[2-8]$ & $<.01$ \\
\hline \multicolumn{5}{|l|}{ Life support limitations } \\
\hline Any life support limitation & $695(12.2)$ & $69(41.3)$ & $68(33)$ & 0.10 \\
\hline Limitation categories $^{c}$ & & & & $<.01$ \\
\hline Withholding & $504(8.9)$ & $31(18.6)$ & $16(7.8)$ & . \\
\hline Withdrawal & $314(5.5)$ & $38(22.8)$ & $52(25.2)$ & . \\
\hline $\begin{array}{l}\text { Time from ICU to first } \\
\text { limitation, days }\end{array}$ & $6[2-15]$ & $5[3-9]$ & $2[1-6]$ & $<.01$ \\
\hline \multicolumn{5}{|l|}{ Outcomes } \\
\hline ICU mortality & $1322(23.3)$ & $92(55.1)$ & $145(70.4)$ & $<.01$ \\
\hline End-of-life outcome & & & & $<.01$ \\
\hline Brain death & 0 & $21(22.8)$ & 68 (46.9) & . \\
\hline
\end{tabular}

Abbreviations: ICU, Intensive Care Unit; GCS, Glasgow Coma Scale; SAPS, Simplified Acute Physiology Score.

${ }^{a}$ Intracranial hemorrhage and subarachnoid hemorrhage; ${ }^{b}$ Comparison of acute ischemic stroke patients and hemorrhagic stroke patients; ${ }^{c}$ If more than one limitation of life support occurred, the most active limitation (withdrawing $>$ withholding) defined the limitation category 


\begin{tabular}{|c|c|c|c|c|}
\hline $\begin{array}{l}\text { Variable } \\
N(\%) \text { or median [Q1 - Q3] }\end{array}$ & $\begin{array}{l}\text { Non-brain-injured } \\
\text { patients } \\
n=5683\end{array}$ & $\begin{array}{l}\text { Ischemic stroke } \\
\text { patients } \\
n=167\end{array}$ & $\begin{array}{l}\text { Hemorrhagic stroke } \\
\text { patients }^{a} \\
n=206\end{array}$ & $\mathrm{p}^{b}$ \\
\hline $\begin{array}{l}\text { Death without limitation of } \\
\text { life support }\end{array}$ & 755 (57.1) & $7(7.6)$ & $12(8.3)$ & . \\
\hline $\begin{array}{l}\text { Death following a limitation } \\
\text { of life support }\end{array}$ & 567 (42.9) & $64(69.6)$ & $65(44.8)$ & . \\
\hline \multicolumn{5}{|c|}{$\begin{array}{l}\text { Abbreviations: ICU, Intensive Care Unit; GCS, Glasgow Coma Scale; SAPS, Simplified Acute Physiology } \\
\text { Score. }\end{array}$} \\
\hline \multicolumn{5}{|c|}{$\begin{array}{l}{ }^{a} \text { Intracranial hemorrhage and subarachnoid hemorrhage; }{ }^{b} \text { Comparison of acute ischemic stroke } \\
\text { patients and hemorrhagic stroke patients; }{ }^{c} \text { If more than one limitation of life support occurred, the } \\
\text { most active limitation (withdrawing > withholding) defined the limitation category }\end{array}$} \\
\hline
\end{tabular}

During their ICU stay, 137/373 (37\%) stroke patients and 695/5683 (12\%) non-brain-injured patients underwent a limitation of life support. The frequency of such limitation was $41 \%$ (69/167 patients) for ischemic strokes and 33\% (68/206 patients) for hemorrhagic strokes $(p=0.1)$. In a Fine and Gray subdistribution multivariable competing risk model adjusted on age, comorbidities, and severity at ICU admission, we found that having an ICU admission diagnosis of ischemic stroke was associated with a 3.6-fold increased (95\% confidence interval $(\mathrm{Cl})$ [2.78-4.65]) risk of undergoing a limitation of life support, as compared to the non-brain-injured population. Similarly, having an ICU admission diagnosis of hemorrhagic stroke was associated with a 3.9-fold increased ( $95 \% \mathrm{Cl}$ [2.97-5.11]) risk of qualifying for limitation of life support, as compared to the non-brain-injured population (Additional file 2).

Among patients who underwent life support limitation, withdrawal was the predominant limitation category in the stroke population (ischemic strokes, 38/69 (55\%); hemorrhagic strokes, 52/68 (76\%)), whereas withholding was the most frequent category in the non-brain-injured population (381/695 (55\%)). Time from ICU admission to the first limitation of life support differed between ischemic stroke and hemorrhagic strokes (5 [3-9] vs $2[1-6]$ days, $p<0.01)$. The daily ICU incidence rate of life support limitation according to stroke subtype or absence of brain injury is presented in Fig. 1 and shows different time patterns between stroke and non-brain-injured patients.

ICU mortality was 92/167 (55\%), 145/206 (70\%), and 1322/5683 (23\%) for ischemic stroke, hemorrhagic stroke, and non-brain-injured populations respectively (Table 1). In the non-brain injured population, death following life support limitation occurred in 567/1322 (43\%) cases (Table 1). In the stroke population, death following a limitation of life support occurred in 129/235 (55\%) patients, including 64/90 (70\%) ischemic stroke patients and 65/145 $(45 \%)$ hemorrhagic stroke patients $(p<0.01)$. Brain death occurred in $21 / 90(23 \%)$ ischemic stroke and 68/145 $(47 \%)$ hemorrhagic stroke patients $(p<0.01)$. In the stroke population, ICU mortality after a decision to withhold life support was $43 / 47$ (92\%) and was 86/90 (96\%) after a decision to withdraw life support. 1-year mortality was $100 \%$ for both groups (Table 2). End-of-life outcomes according to the time from ICU admission and by stroke subtype are presented in Fig. 2. From 
the 5th day of ICU stay and beyond, the rate of death following life support limitation exceeded $80 \%$ in ischemic stroke patients, and $70 \%$ in hemorrhagic stroke patients. 
Table 2

Characteristics of the stroke population according to limitation of life support category

\begin{tabular}{|c|c|c|c|c|}
\hline \multirow{2}{*}{$\begin{array}{l}\text { Variable } \\
\text { N (\%) or median [Q1 - Q3] }\end{array}$} & \multicolumn{3}{|c|}{ Limitation of life support $^{a}$} & \multirow[t]{2}{*}{$\mathbf{p}$} \\
\hline & $\begin{array}{l}\text { No limitation } \\
n=236\end{array}$ & $\begin{array}{l}\text { Withholding } \\
n=47\end{array}$ & $\begin{array}{l}\text { Withdrawal } \\
n=90\end{array}$ & \\
\hline \multicolumn{5}{|l|}{ Demographics/history } \\
\hline Age, years & $\begin{array}{l}65.5[56.3- \\
74.1]\end{array}$ & $\begin{array}{l}72.5[62.4- \\
77.6]\end{array}$ & $\begin{array}{l}73.8[62.7- \\
81.3]\end{array}$ & $<.01$ \\
\hline Male sex & $134(56.8)$ & $33(70.2)$ & $54(60)$ & 0.23 \\
\hline Charlson comorbidity index $\geq 1$ & $120(50.8)$ & $28(59.6)$ & $52(57.8)$ & 0.36 \\
\hline \multicolumn{5}{|l|}{ Hospital characteristics } \\
\hline University hospital & $137(58.1)$ & $25(53.2)$ & $61(67.8)$ & 0.17 \\
\hline Stroke unit on-site & $220(93.2)$ & $42(89.4)$ & $80(88.9)$ & 0.37 \\
\hline Neurosurgery unit on-site & $119(50.4)$ & $18(38.3)$ & $50(55.6)$ & 0.16 \\
\hline ICU type & & & & 0.2 \\
\hline Medical & $129(54.7)$ & $21(44.7)$ & $58(64.4)$ & . \\
\hline Mixed & $104(44.1)$ & $25(53.2)$ & $30(33.3)$ & . \\
\hline Surgical & $3(1.3)$ & $1(2.1)$ & $2(2.2)$ & . \\
\hline ICU authorized for organ donation & $161(68.2)$ & $30(63.8)$ & $54(60)$ & 0.36 \\
\hline \multicolumn{5}{|l|}{$\begin{array}{l}\text { Ischemic stroke characteristics }(n= \\
\text { 167) }\end{array}$} \\
\hline Location & & & & 0.18 \\
\hline Anterior circulation & $67 / 98(68.4)$ & $17 / 30(56.7)$ & 20/38 (52.6) & . \\
\hline Vertebrobasilar circulation & $31 / 98(31.6)$ & $13 / 30(43.3)$ & 18/38 (47.4) & . \\
\hline Acute phase therapy $b$ & $26 / 98(26.5)$ & $2(6.5)$ & $6(15.8)$ & 0.04 \\
\hline
\end{tabular}

Abbreviations: ICU, Intensive Care Unit; GCS, Glasgow Coma Scale; SAPS, Simplified Acute Physiology Score.

${ }^{a}$ If more than one limitation of life support occurred, the most active limitation (withdrawing > withholding) defined the limitation category; ${ }^{b}$ Thrombolysis or endovascular thrombectomy; ${ }^{c}$ Intracranial hemorrhage and subarachnoid hemorrhage; ${ }^{d}$ Neurosurgery or embolization; ${ }^{e} 22 / 373$ $(6 \%)$ stroke patients were lost to follow-up and censored at $47[23 ; 153]$ days 


\begin{tabular}{|c|c|c|c|c|}
\hline \multirow{3}{*}{$\begin{array}{l}\text { Variable } \\
\text { N (\%) or median [Q1 - Q3] }\end{array}$} & \multicolumn{3}{|c|}{ Limitation of life support ${ }^{a}$} & \multirow[t]{3}{*}{ p } \\
\hline & No limitation & Withholding & Withdrawal & \\
\hline & $n=236$ & $n=47$ & $\mathrm{n}=90$ & \\
\hline $\begin{array}{l}\text { Time from stroke to ICU admission, } \\
\text { days }\end{array}$ & $2[1-7]$ & $1[1-6]$ & $1[1-2]$ & 0.05 \\
\hline \multicolumn{5}{|l|}{$\begin{array}{l}\text { Hemorrhagic stroke }{ }^{c} \text { characteristics ( } \mathrm{n} \\
=206 \text { ) }\end{array}$} \\
\hline \multicolumn{4}{|l|}{ Location } & $<.01$ \\
\hline Deep & $32 / 138$ (23.2) & 9/16 (56.3) & $5 / 52(9.6)$ & . \\
\hline Lobar & $85 / 138(61.6)$ & $6 / 16(37.5)$ & $34 / 52(65.4)$ & . \\
\hline Infratentorial & $21 / 138(15.2)$ & $1 / 16(6.3)$ & $13 / 52(25)$ & . \\
\hline Acute phase therapy ${ }^{d}$ & $27 / 138(19.6)$ & 0 & $7 / 52(13.5)$ & 0.11 \\
\hline $\begin{array}{l}\text { Time from stroke to ICU admission, } \\
\text { days }\end{array}$ & $1[1-2]$ & $1[1-1.5]$ & $1[1-1]$ & 0.13 \\
\hline \multicolumn{5}{|l|}{ ICU characteristics } \\
\hline GCS at admission & $5[3-9]$ & $4[3-8]$ & $3[3-6]$ & $<.01$ \\
\hline SAPS II & $56[45-68.5]$ & $66[54-78]$ & $62.5[53-74]$ & $<.01$ \\
\hline $\begin{array}{l}\text { Duration of mechanical ventilation, } \\
\text { days }\end{array}$ & $3[2-8]$ & $5[2-9]$ & $5[2-8]$ & 0.07 \\
\hline Vasopressor support & $127(53.8)$ & $18(38.3)$ & $34(37.8)$ & 0.01 \\
\hline ICU length of stay, days & $4[2-11]$ & $6[2-11]$ & $6[3-9]$ & 0.49 \\
\hline \multicolumn{5}{|l|}{ Outcomes } \\
\hline ICU mortality & $108(45.8)$ & $43(91.5)$ & $86(95.6)$ & $<.01$ \\
\hline Hospital mortality & $126(53.4)$ & $45(95.7)$ & $89(98.9)$ & $<.01$ \\
\hline 1-year mortality ${ }^{e}$ & $138(64.2)$ & $46(100)$ & $90(100)$ & $<.01$ \\
\hline \multicolumn{5}{|c|}{$\begin{array}{l}\text { Abbreviations: ICU, Intensive Care Unit; GCS, Glasgow Coma Scale; SAPS, Simplified Acute Physiology } \\
\text { Score. }\end{array}$} \\
\hline \multicolumn{5}{|c|}{$\begin{array}{l}{ }^{a} \text { If more than one limitation of life support occurred, the most active limitation (withdrawing > } \\
\text { withholding) defined the limitation category; }{ }^{b} \text { Thrombolysis or endovascular thrombectomy; }{ }^{c} \\
\text { Intracranial hemorrhage and subarachnoid hemorrhage; }{ }^{d} \text { Neurosurgery or embolization; }{ }^{e} 22 / 373 \\
(6 \%) \text { stroke patients were lost to follow-up and censored at } 47[23 ; 153] \text { days }\end{array}$} \\
\hline
\end{tabular}


Univariate analysis of factors associated with life support limitation is presented in Table 2 . In the subset of ischemic stroke patients, the only variable significantly associated with a decision to limit life support was the location of stroke (vertebrobasilar vs. anterior circulation location, sHR 1.61 [1.01-2.59]) (Fig. 3). In the subset of hemorrhagic stroke patients, variables associated with a decision to limit life support were age > 70 years (sHR 2.29 [1.43; 3.69]), a GCS < 8 at ICU admission (sHR 2.15 [1.08-4.3]) and the nonneurologic SOFA score at ICU admission (sHR 0.89 [0.82; 0.97]) (Fig. 3). The period of inclusion in the study, when forced into each model, was not significantly associated with a decision to limit life support (Additional files 3 and 4).

\section{Discussion}

The $37 \%$ rate of life support limitation observed in our cohort is consistent with rates reported in previous studies conducted in intracranial hemorrhage patients, ranging from 34 to $43 \%[7,8]$. Of note, our study provides unique data regarding the limitation rate in the specific population of ischemic stroke patients requiring IMV. Furthermore, we present accurate estimates, as they integrate the competitive risk of dying without receiving a decision of limitation. These models are particularly relevant in populations with very high case-fatality rates where death precludes the occurrence of the outcome of interest $[25,28]$. Our results confirm that stroke patients under IMV are a population submitted to a high incidence of end-oflife decisions, and thus deserve a more thorough evaluation [16, 29]. A prospective multicentre study investigating 1-year outcomes, ethical issues, and care pathways of acute stroke patients requiring IMV in the ICU, is ongoing (NCT 03335995) [30].

We found that $54 \%$ of stroke patient ICU deaths and $43 \%$ of those of non-brain-injured patients were preceded by a decision to limit life support. These rates are consistent with those reported in the general ICU population, ranging from $47-53 \%[10,15,31]$. When evaluating end-of-life outcomes by stroke subtype, it is interesting to note that ischemic stroke patients had a higher proportion of death following a decision to limit life support than hemorrhagic stroke patients, probably because hemorrhagic stroke patients had a higher proportion of brain death.

The highest incidence of life support limitation during ICU stay occurred during the first 4 days. For hemorrhagic strokes in particular, the incidence of limitation was highest within the $48 \mathrm{~h}$ following ICU admission, with a more than 2 -fold incidence than any other period of the ICU stay. This result could notably be explained by a higher rate of direct ICU admission from home or the emergency department in hemorrhagic stroke patients, where physicians might initiate IMV without knowing neither the patient's medical history nor the extent of brain injury. Early decisions of life support limitation have been associated with a higher risk of short-term mortality independently of patient factors, suggesting that some of these decisions may be undue [7, 8, 32]. Bias that may result in underuse of life support in severe stroke patients include erroneous prognostic estimates [33-35], misunderstanding patient's values and expectation [36], and undervaluing the future patient's health state (disability paradox) [29, 37]. The influence of cognitive bias in the decision-making process must also be acknowledged, and may be as important as patient factors [38]. Inappropriate prognostic pessimism and premature limitations of life 
support define the mechanism by which self-fulfilling prophecies occur [39]. As such, life support limitation within $48 \mathrm{~h}$ of ICU admission is not recommended in intracranial hemorrhage patients [40], and time-limited ICU trials should be proposed in severe stroke patients.

The most commonly described risk factors for receiving a decision to limit life support in the general ICU population are age, the presence of chronic diseases, and clinical severity at ICU admission [11-13, 41, 42]. In critically ill brain-injured patients, age and a low GCS are the most frequently reported [6, 43]. It is interesting to note that in our study, risk factors appear to differ between ischemic and hemorrhagic stroke patients. For the latter, the usual patient-related risk factors were found (i.e. age and neurological severity), with the notable addition of non-neurological organ failure that appeared to play a protective role. We hypothesize that intensivists would be more inclined to continue aggressive care in these patients because non-neurologic organ failure may be more reversible and without obvious impact on functional outcome, as compared to neurological failure. For ischemic stroke patients, however, neither age nor comorbidities were associated with life support limitation. We hypothesize that there was an important left censoring in our study (i.e. patients having undergone life support limitation before ICU admission) that might have mitigated the effect of age and comorbidities $[44,45]$.

The strengths of our study include a multicenter population from a high-quality prospective database. The relatively small number of patients included, considering the study period and the 14 ICUs, is due to the fact that several ICUs did not contribute throughout the 12 years, and some used only a fraction of their beds to feed the database. Our study also has limitations. First, the OUTCOMEREA database was not built specifically for stroke studies, and all data regarding stroke are retrospective, collected from hospitalization records. As a result, some data, such as the stroke volume, are lacking. Furthermore, data regarding the modality of treatments withheld or withdrawn, and the reason for undertaking a life support limitation was not available. Second, end-of-life decision-making is a complex process, and we did not explore all the determinants that lead to a limitation of life support, which may include patient- or surrogate-centered determinants, and physicians' personal beliefs [16, 29]. Third, our study population excluded stroke patients that were critically ill, but were not referred to the ICU because of care-limiting decisions made by the neurologist or the emergency physician in charge. Fourth, our results and conclusion may apply only for the setting and culture we recruited the patients from, as this is an exclusively French cohort including only medical and mixed ICUs. As only $50 \%$ of the cohort were treated with on-site neurosurgery and interventional radiology, we may have selected a population with a high proportion of patients not eligible for acute phase stroke therapy. However, as all multivariate models were stratified on centers of inclusion, we believe that this effect was accounted for. Fifth, data on functional outcomes in survivors could not be reported.

\section{Conclusions}

In this secondary data use of a prospective multicenter cohort study of critically ill patients requiring IMV, we showed that life support limitation was more than 3 times more frequent in stroke patients than in non-brain injured patients. There were significant differences in timing and risk factors for limitation of 
life support between ischemic and hemorrhagic strokes. In ventilated stroke patients, early decisions to limit life support are frequent and a high proportion of deaths follow such decisions. These findings warrant further investigations to clarify the impact of life support limitation on prognostication models.

\section{List Of Abbreviations}

95\% Cl: 95\% Confidence Interval

GCS: Glasgow Coma Score

ICU: Intensive Care Unit

IMV: Invasive Mechanical Ventilation

SAPS: Simplified Acute Physiology Score

sHR: subdistribution Hazard Ratio

SOFA: Sequential Organ Failure Assessment

\section{Declarations}

\section{Ethics approval and consent to participate}

The OUTCOMEREA database has been approved by the French Advisory Committee for Data Processing in Health Research (CCTIRS) and the French Informatics and Liberty Commission (CNIL, registration no. 8999262). The database protocol was submitted to the Institutional Review Board of the ClermontFerrand University hospital (Clermont-Ferrand, France), who waived the need for informed consent (IRB no. 5891).

\section{Consent to participate}

Not applicable.

\section{Availability of data and materials}

The datasets used and/or analyzed during the current study are available from the corresponding author on reasonable request.

\section{Competing interests}

Work Under Consideration for Publication: no competing interest. 
Relevant financial activities outside the submitted work: Guillaume Thiéry (Gilead-Kite).

\section{Funding}

None.

\section{Authors' contributions}

Conception and design of the study: EDM, SR, RS, JFT.

Data acquisition: all authors

Analysis and interpretation of data: EDM, SR, RS, JFT

Manuscript Draft: EDM

Manuscript revision and approval: all authors

\section{Acknowledgments}

\section{Members of the OUTCOMEREA Study Group-Scientific Committee}

Jean-François Timsit (Medical and Infectious Diseases ICU, Bichat-Claude Bernard Hospital, Paris, France; UMR 1137 Inserm - Paris Diderot university IAME, F75018, Paris); Elie Azoulay (Medical ICU, Saint Louis Hospital, Paris, France); Maïté Garrouste-Orgeas (Paliative care, Institut franco Britanique, Paris, France); Jean-Ralph Zahar (Infection Control Unit, Avicenne Hospital, Bobigny, France); Bruno Mourvillier (Medical ICU, CHU Reims, France); Michael Darmon (Medical ICU, APHP Saint Louis hospital Paris, France).

\section{Biostatistical and information system expertise}

Jean-Francois Timsit (Medical and Infectious Diseases ICU, Bichat-Claude Bernard Hospital, Paris, France; UMR 1137 Inserm -Paris Diderot University IAME, F75018, Paris); Corinne Alberti (Medical Computer Sciences and Biostatistics Department, Robert Debré Hospital, Paris, France); Stephane Ruckly (OUTCOMEREA Organization and Inserm UMR 1137 IAME, F75018, Paris); Sébastien Bailly (Grenoble University Hospital Inserm UMR 1137 IAME, F75018, Paris) and Aurélien Vannieuwenhuyze (Tourcoing, France).

\section{Investigators of the OUTCOMEREA database:}


Christophe Adrie (ICU, CH Melun, and Physiology, Cochin Hospital, Paris, France); Carole Agasse (Medical ICU, University Hospital Nantes, France); Bernard Allaouchiche (ICU, Hospices civils de Lyon, Lyon sud, Lyon, France); Olivier Andremont (ICU, Bichat Hospital, Paris, France); Pascal Andreu (CHU Dijon, Dijon, France); Laurent Argaud (Medical ICU, Hospices Civils de Lyon, Lyon, France); Claire Ara-Somohano (Medical ICU, University Hospital, Grenoble, France); Elie Azoulay (Medical ICU, Saint Louis Hospital, Paris, France); Francois Barbier (Medical-Surgical ICU, Orleans, France), Jean-Pierre Bedos (ICU, Versailles Hospital, Le Chesnay, France); Thomas Baudry (Medial ICU, Edouard Herriot Hospital, Lyon France), Jérome Bedel (ICU, Versailles Hospital, Le Chesnay, France), Julien Bohé (ICU, Hôpital Pierre Benite, Lyon France), Lila Bouadma (ICU, Bichat Hospital, Paris, France); Jeremy Bourenne (Réanimation des Urgences, Timone-2; APHM, Marseille, France); Noel Brule (Medical ICU, University Hospital Nantes, France); Frank Chemouni (Polyvalent ICU, Grand Hôpital de l'Est Francilien, Jossigny, France) ; Julien Carvelli (Réanimation des Urgences, Timone-2; APHM, Marseille, France); Elisabeth Coupez (ICU, G Montpied Hospital, Clermont-Ferrand, France); Martin Cour (Medial ICU, Edouard Heriot Hospital, Lyon France), Michael Darmon (ICU, APHP St louis, Paris France); Claire Dupuis (ICU, G Montpied Hospital, ClermontFerrand, France), Etienne de Montmollin (ICU, Bichat Hospital, Paris, France), Loa Dopeux (ICU, G Montpied Hospital, Clermont-Ferrand, France); Anne-Sylvie Dumenil (Antoine Béclère Hospital, Clamart, France); Jean-Marc Forel (AP HM, Medical ICU, Hôpital Nord Marseille), Marc Gainnier (Réanimation des Urgences, Timone-2; APHM, Marseille, France), Charlotte Garret (Medical ICU, University Hospital Nantes, France); Dany Goldgran-Tonedano (CH le Raincy-Montfermeil; France); Steven Grangé (ICU, CHU Rouen, France), Antoine Gros (ICU, Versailles Hospital, Versailles, France), Hédia Hammed (CH le RaincyMontfermeil) ; Akim Haouache (Surgical ICU, H Mondor Hospital, Creteil, France); Tarik Hissem (ICU, Eaubonne, France), Vivien Hong Tuan Ha (ICU, CH Meaux, France); Sébastien Jochmans (ICU, CH Melun); Jean-Baptiste Joffredo (ICU, G Montpied Hospital, Clermont-Ferrand, France); Hatem Kallel (ICU, Cayenne General Hospital, Cayenne, France); Guillaume Lacave (ICU, Versailles Hospital, Le Chesnay, France), Virgine Laurent (ICU, Versailles Hospital, Le Chesnay, France), Alexandre Lautrette (ICU, G Montpied Hospital, Clermont-Ferrand, France); Clément Le Bihan (ICU, Bichat Hospital, Paris, France), Virgine Lemiale (Medical ICU, Saint Louis Hospital, Paris, France); David Luis (Médecine Intensive et Réanimation, CH Simone Veil, Beauvais, France), Guillaume Marcotte (Surgical ICU, Hospices Civils de Lyon, Lyon, France); Jordane Lebut (ICU, Bichat Hospital, Paris, France); Bruno Mourvillier (ICU, CHU Reims, Reims, France); Mathild Neuville (ICU, Foch Hospital, Paris, France) ; Laurent Nicolet (Medical ICU, University Hospital Nantes, France); Johanna Oziel (Medico-Surgical ICU, Hôpital Avicenne APHP, Bobigny, France), Laurent Papazian (Hopital Nord, Marseille, France), Juliette Patrier (ICU, Bichat Hospital, Paris, France), Benjamin Planquette (Pulmonology ICU, George Pompidou Hospital Hospital, Paris, France); Aguila Radjou (ICU, Bichat Hospital, Paris, France), Marie Simon (Medial ICU, Edouard Heriot Hospital, Lyon France), Romain Sonneville (ICU, Bichat Hospital, Paris, France), Jean Reignier (Medical ICU, University Hospital Nantes, France); Bertrand Souweine (ICU, G Montpied Hospital, Clermont-Ferrand, France); Carole Schwebel (ICU, A Michallon Hospital, Grenoble, France); Shidasp Siami (ICU, Etampes Hospital, France); Nicolas Terzi (ICU, A Michallon Hospital, Grenoble, France ); Gilles Troché (ICU, André Mignot Hospital, Le Chesnay, France); Fabrice Thiollieres (ICU, Hospices civils de Lyon, Lyon sud, Lyon, France); Guillaume Thierry (ICU, St Etienne, France); Guillaume Van Der Meersch (Medical Surgical ICU, 
University Hospital Avicenne), Marion Venot (Medical ICU, Saint Louis Hospital, Paris, France); Florent Wallet (ICU, Hospices Civils de Lyon, Lyon sud, Lyon, France); Sondes Yaacoubi (CH le RaincyMontfermeil); Olivier Zambon (Medical ICU, University Hospital Nantes, France); Jonathan Zarka (Reanimation Polyvalente, Centre Hospitalier de Marne la Vallée, France).

\section{Study Monitors}

Mireille Adda, Vanessa Vindrieux, Marion Provent, Sylvie de la Salle, Pauline Enguerrand, Vincent Gobert, Stéphane Guessens, Helene Merle, Nadira Kaddour, Boris Berthe, Samir Bekkhouche, Kaouttar Mellouk, Mélaine Lebrazic, Carole Ouisse, Diane Maugars, Christelle Aparicio, Igor Theodose, Manal Nouacer, Veronique Deiler, Fariza Lamara, Myriam Moussa, Atika Mouaci, Nassima Viguier.

\section{References}

1. Santoli F, De Jonghe B, Hayon J, Tran B, Piperaud M, Merrer J, et al. Mechanical ventilation in patients with acute ischemic stroke: survival and outcome at one year. Intensive Care Med. 2001;27:1141-6.

2. Schielke E, Busch MA, Hildenhagen T, Holtkamp M, Küchler I, Harms L, et al. Functional, cognitive and emotional long-term outcome of patients with ischemic stroke requiring mechanical ventilation. $J$ Neurol. 2005;252:648-54.

3. Milhaud D, Popp J, Thouvenot E, Heroum C, Bonafé A. Mechanical ventilation in ischemic stroke. J Stroke Cerebrovasc Dis. 2004;13:183-8.

4. de Montmollin E, Terzi N, Dupuis C, Garrouste-Orgeas M, da Silva D, Darmon M, et al. One-year survival in acute stroke patients requiring mechanical ventilation: a multicenter cohort study. Ann Intensive Care. 2020;10:53.

5. Sonneville R, Gimenez L, Labreuche J, Smonig R, Magalhaes E, Bouadma L, et al. What is the prognosis of acute stroke patients requiring ICU admission? Intensive Care Med. 2017;43:271-2.

6. Diringer MN, Edwards DF, Aiyagari V, Hollingsworth $\mathrm{H}$. Factors associated with withdrawal of mechanical ventilation in a neurology/neurosurgery intensive care unit: Crit Care Med. 2001;29:1792-7.

7. Zahuranec DB, Brown DL, Lisabeth LD, Gonzales NR, Longwell PJ, Smith MA, et al. Early care limitations independently predict mortality after intracerebral hemorrhage. Neurology. 2007;68:16517.

8. Creutzfeldt CJ, Becker KJ, Weinstein JR, Khot SP, McPharlin TO, Ton TG, et al. Do-not-attemptresuscitation orders and prognostic models for intraparenchymal hemorrhage. Crit Care Med. 2011;39:158-62.

9. Azoulay É, Metnitz B, Sprung CL, Timsit J-F, Lemaire F, Bauer P, et al. End-of-life practices in 282 intensive care units: data from the SAPS 3 database. Intensive Care Med. 2009;35:623-30. 
10. Ferrand E, Robert R, Ingrand P, Lemaire F. Withholding and withdrawal of life support in intensive-care units in France: a prospective survey. The Lancet. 2001;357:9-14.

11. Wunsch H, Harrison DA, Harvey S, Rowan K. End-of-life decisions: a cohort study of the withdrawal of all active treatment in intensive care units in the United Kingdom. Intensive Care Med. 2005;31:82331.

12. Quill CM, Ratcliffe SJ, Harhay MO, Halpern SD. Variation in Decisions to Forgo Life-Sustaining Therapies in US ICUs. Chest. 2014;146:573-82.

13. Lobo SM, De Simoni FHB, Jakob SM, Estella A, Vadi S, Bluethgen A, et al. Decision-Making on Withholding or Withdrawing Life Support in the ICU. Chest. 2017;152:321-9.

14. Lautrette A, Garrouste-Orgeas M, Bertrand P-M, Goldgran-Toledano D, Jamali S, Laurent V, et al. Respective impact of no escalation of treatment, withholding and withdrawal of life-sustaining treatment on ICU patients' prognosis: a multicenter study of the Outcomerea Research Group. Intensive Care Med. 2015;41:1763-72.

15. Lesieur O, Leloup M, Gonzalez F, Mamzer M-F. Withholding or withdrawal of treatment under French rules: a study performed in 43 intensive care units. Ann Intensive Care. 2015;5:56.

16. Geurts M, Macleod MR, van Thiel GJMW, van Gijn J, Kappelle LJ, van der Worp HB. End-of-life decisions in patients with severe acute brain injury. Lancet Neurol. 2014;13:515-24.

17. Wartenberg KE, Hwang DY, Häusler KG, Muehlschlegel S, Sakowitz OW, Madžar D, et al. Gap Analysis Regarding Prognostication in Neurocritical Care: A Joint Statement from the German Neurocritical Care Society and the Neurocritical Care Society. Neurocrit Care. 2019;31:231-44.

18. Truche A-S, Darmon M, Bailly S, Clec'h C, Dupuis C, Misset B, et al. Continuous renal replacement therapy versus intermittent hemodialysis in intensive care patients: impact on mortality and renal recovery. Intensive Care Med. 2016;42:1408-17.

19. The GBD 2016 Lifetime Risk of Stroke Collaborators. Global, Regional, and Country-Specific Lifetime Risks of Stroke, 1990 and 2016. N Engl J Med. 2018;379:2429-37.

20. Sprung CL, Ricou B, Hartog CS, Maia P, Mentzelopoulos SD, Weiss M, et al. Changes in End-of-Life Practices in European Intensive Care Units From 1999 to 2016. JAMA. 2019;322:1692-704.

21. Le Gall JR, Lemeshow S, Saulnier F. A new Simplified Acute Physiology Score (SAPS II) based on a European/North American multicenter study. JAMA. 1993;270:2957-63.

22. Vincent JL, Moreno R, Takala J, Willatts S, De Mendonça A, Bruining H, et al. The SOFA (Sepsisrelated Organ Failure Assessment) score to describe organ dysfunction/failure. On behalf of the Working Group on Sepsis-Related Problems of the European Society of Intensive Care Medicine. Intensive Care Med. 1996;22:707-10.

23. Teasdale G, Jennett B. Assessment of coma and impaired consciousness. A practical scale. Lancet. 1974;2:81-4.

24. Charlson ME, Pompei P, Ales KL, MacKenzie CR. A new method of classifying prognostic comorbidity in longitudinal studies: Development and validation. J Chronic Dis. 1987;40:373-83. 
25. Lau B, Cole SR, Gange SJ. Competing Risk Regression Models for Epidemiologic Data. Am J Epidemiol. 2009;170:244-56.

26. Mark NM, Rayner SG, Lee NJ, Curtis JR. Global variability in withholding and withdrawal of lifesustaining treatment in the intensive care unit: a systematic review. Intensive Care Med. 2015;41:1572-85.

27. Vesin A, Azoulay E, Ruckly S, Vignoud L, Rusinovà K, Benoit D, et al. Reporting and handling missing values in clinical studies in intensive care units. Intensive Care Med. 2013;39:1396-404.

28. de Montmollin E, Ruckly S, Schwebel C, Philippart F, Adrie C, Mariotte E, et al. Pneumonia in acute ischemic stroke patients requiring invasive ventilation: Impact on short and long-term outcomes. J Infect. 2019;79:220-7.

29. G. Holloway R. Prognosis and Decision Making in Severe Stroke. JAMA. 2005;294:725-33.

30. Sonneville R, Mazighi M, Bresson D, Crassard I, Crozier S, de Montmollin E, et al. Outcomes of Acute Stroke Patients Requiring Mechanical Ventilation: Study Protocol for the SPICE Multicenter Prospective Observational Study. Neurocrit Care. 2020;32:624-9.

31. Prendergast TJ, Claessens MT, Luce JM. A National Survey of End-of-life Care for Critically III Patients. Am J Respir Crit Care Med. 1998;158:1163-7.

32. Mohammed MA, Mant J, Bentham L, Stevens A, Hussain S. Process of care and mortality of stroke patients with and without a do not resuscitate order in the West Midlands, UK. Int J Qual Health Care. 2006;18:102-6.

33. Becker KJ, Baxter AB, Cohen WA, Bybee HM, Tirschwell DL, Newell DW, et al. Withdrawal of support in intracerebral hemorrhage may lead to self-fulfilling prophecies. Neurology. 2001;56:766-72.

34. Frick S, Uehlinger DE, Zuercher Zenklusen RM. Medical futility: Predicting outcome of intensive care unit patients by nurses and doctors-A prospective comparative study*: Crit Care Med. 2003;31:45661.

35. Geurts M, de Kort FAS, de Kort PLM, van Tuijl JH, Kappelle LJ, van der Worp HB. Predictive accuracy of physicians' estimates of outcome after severe stroke. Quinn TJ, editor. PLOS ONE. 2017;12:e0184894.

36. Fried TR, Bradley EH, Towle VR. Valuing the Outcomes of Treatment: Do Patients and Their Caregivers Agree? Arch Intern Med. 2003;163:2073.

37. Albrecht GL, Devlieger PJ. The disability paradox: high quality of life against all odds. Soc Sci Med. 1999;48:977-88.

38. Rohaut B, Claassen J. Decision making in perceived devastating brain injury: a call to explore the impact of cognitive biases. Br J Anaesth. 2018;120:5-9.

39. Rabinstein AA, Diringer MN. Withholding care in intracerebral hemorrhage. Realistic compassion or self-fulfilling prophecy? Neurology. 2007;68:1647-8.

40. Hemphill JC, Greenberg SM, Anderson CS, Becker K, Bendok BR, Cushman M, et al. Guidelines for the Management of Spontaneous Intracerebral Hemorrhage. Stroke. 2015;46:2032-60. 
41. Sprung CL, Cohen SL, Sjokvist P, Baras M, Bulow H-H, Hovilehto S, et al. End-of-Life Practices in European Intensive Care Units. JAMA. 2003;290:790-7.

42. Roger C, Morel J, Molinari N, Orban JC, Jung B, Futier E, et al. Practices of end-of-life decisions in 66 southern French ICUs 4years after an official legal framework: A 1-day audit. Anaesth Crit Care Pain Med. 2015;34:73-7.

43. Kowalski RG, Chang TR, Carhuapoma JR, Tamargo RJ, Naval NS. Withdrawal of Technological Life Support Following Subarachnoid Hemorrhage. Neurocrit Care. 2013;19:269-75.

44. Qureshi Al, Adil MM, Suri MFK. Rate of Utilization and Determinants of Withdrawal of Care in Acute Ischemic Stroke Treated With Thrombolytics in USA: Med Care. 2013;51:1094-100.

45. Parry-Jones AR, Paley L, Bray BD, Hoffman AM, James M, Cloud GC, et al. Care-limiting decisions in acute stroke and association with survival: analyses of UK national quality register data. Int J Stroke. 2016;11:321-31.

\section{Figures}

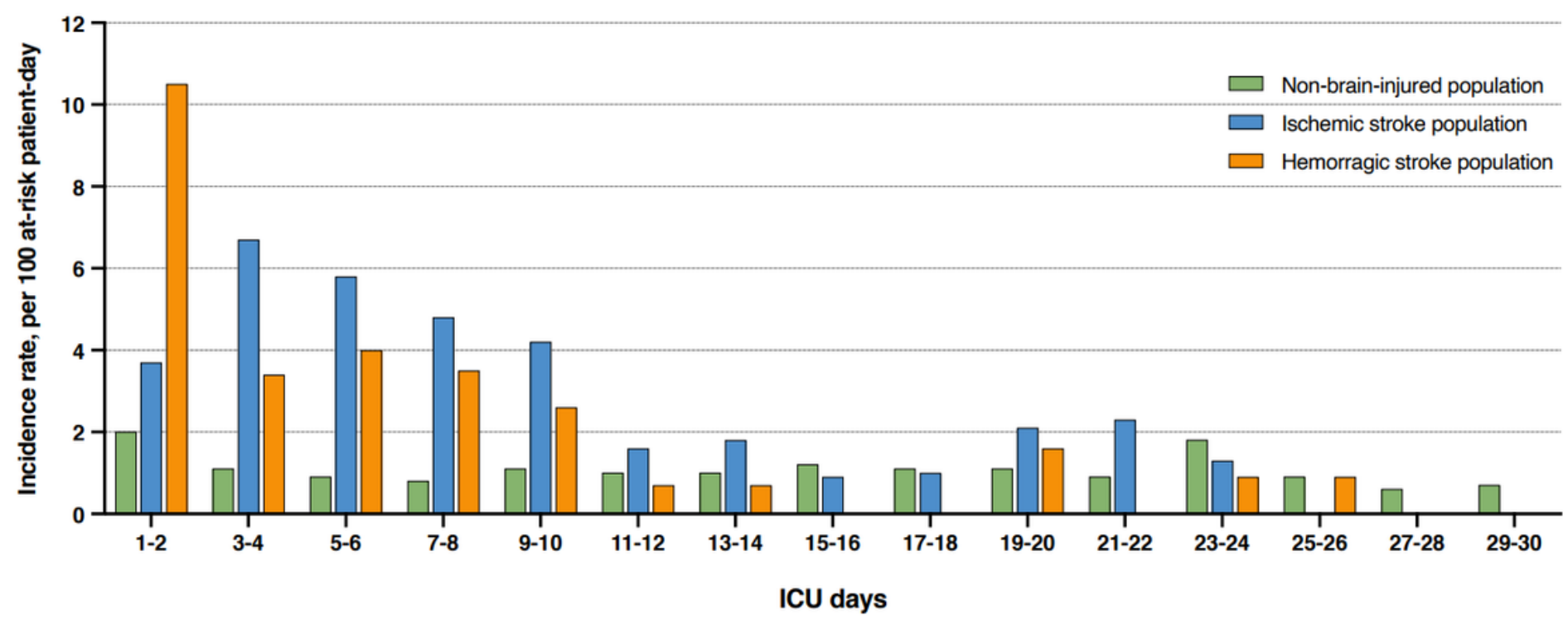

\section{Figure 1}

Daily ICU incidence rate of life support limitations according to stroke subtype or absence of brain-injury 


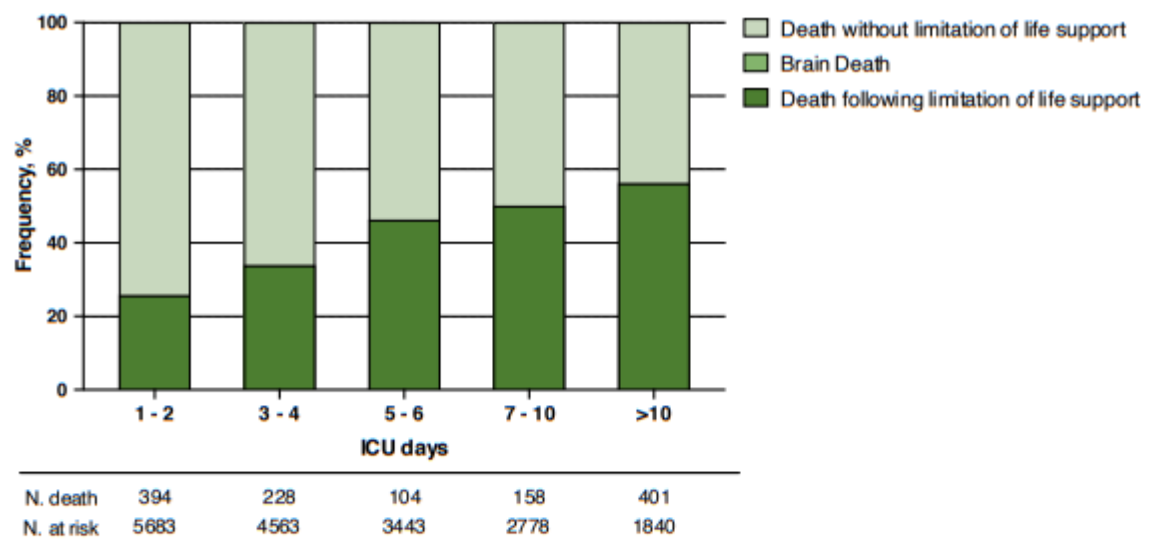

b

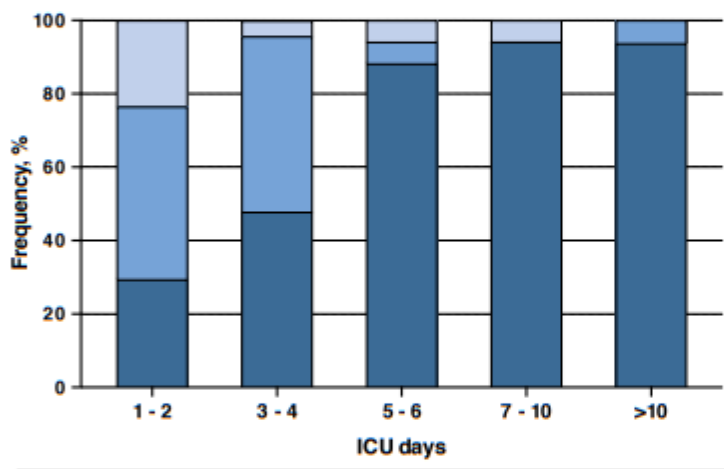

$\square$ Death without limitation of life support $\square$ Brain Death

$\square$ Death following limitation of life support

\begin{tabular}{lccccc}
\hline N. death & 17 & 23 & 17 & 17 & 16 \\
N. at risk & 167 & 146 & 113 & 84 & 58
\end{tabular}

C

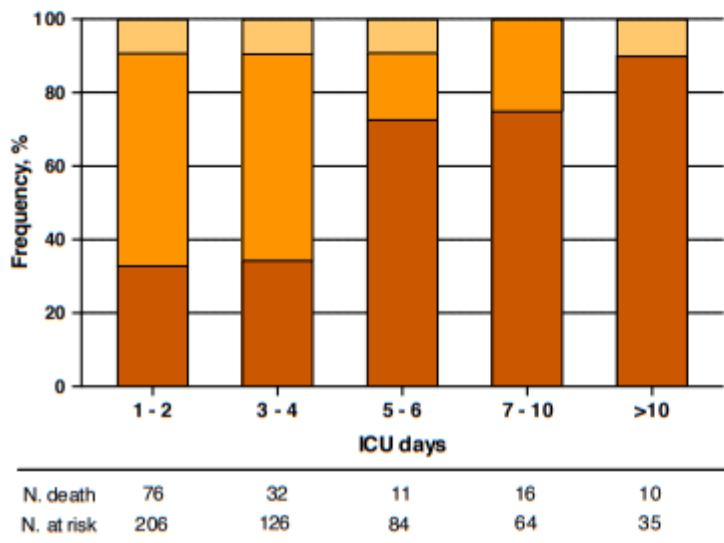

Figure 2

End-of-life outcome according to length of ICU stay (days): comparison between non-brain-injured patients and stroke subtypes. a. Non-brain-injured patients; b. Ischemic stroke patients; c. Hemorrhagic stroke patients. 


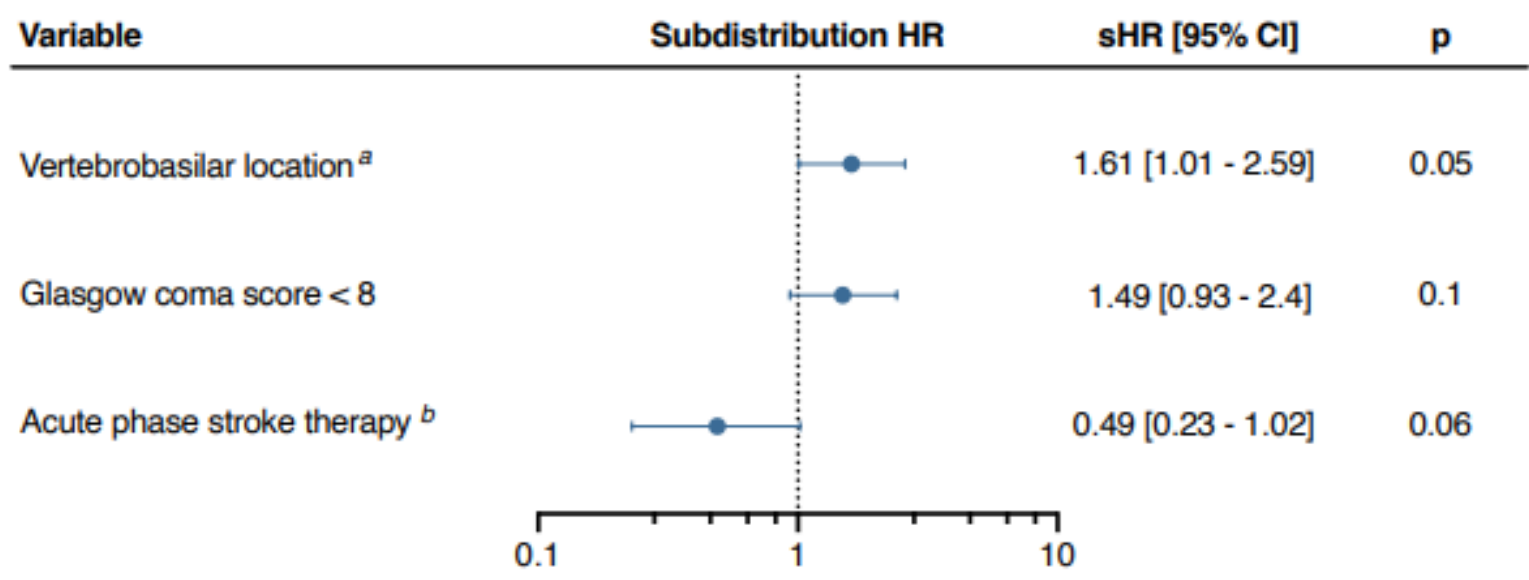

b

\begin{tabular}{|c|c|c|c|}
\hline Variable & Subdistribution HR & sHR $[95 \% \mathrm{Cl}]$ & p \\
\hline Age $>70$ years & $\longmapsto$ & $2.29[1.43-3.69]$ & $<0.01$ \\
\hline Glasgow coma score $<8$ & $\bullet$ & $2.15[1.08-4.3]$ & 0.03 \\
\hline Male sex & $\longrightarrow$ & $1.49[0.96-2.32]$ & 0.07 \\
\hline Non-neurologic SOFA at admission ${ }^{c}$ & $\bullet$ & $0.89[0.82-0.97]$ & $<0.01$ \\
\hline $\begin{array}{r}\Gamma \\
0.1\end{array}$ & $\begin{array}{l}1 \\
1\end{array}$ & & \\
\hline
\end{tabular}

\section{Figure 3}

Fine and Gray sub-distribution hazard analysis for the occurrence of life support limitations, and death without such limitation as the competing event a. Ischemic stroke patients; b. Hemorrhagic stroke patients. Abbreviations: ICU, Intensive Care Unit; sHR, subdistribution Hazard Ratio; $\mathrm{Cl}$, Confidence Interval; SOFA, Sequential Organ Failure Assessment. a versus anterior circulation location; b Thrombolysis or endovascular thrombectomy; c Per SOFA point

\section{Supplementary Files}

This is a list of supplementary files associated with this preprint. Click to download.

- AdditionalMaterial.docx 